\title{
Attitude and practices of obstetricians and gynecologists towards involvement of physiotherapists in management of obstetric and gynecologic conditions
}

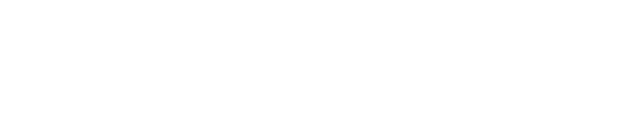

Nse A Odunaiya'

Temitayo Ilesanmi'

Adeniran O Fawole ${ }^{2}$ Oluwafemi O Oguntibeju ${ }^{3}$

'Department of Physiotherapy, ${ }^{2}$ Department of Obstetrics and Gynecology, College of Medicine, University of Ibadan, Ibadan, Nigeria; ${ }^{3}$ Department of Biomedical Sciences, Faculty of Health and Wellness Sciences, Bellville, South Africa
Correspondence: OO Oguntibeju Department of Biomedical Sciences, Faculty of Health and Wellness Sciences, Cape Peninsula University of Technology, Bellville 7535, South Africa

Tel +27219538495

Fax +27219538490

Email oguntibejuo@cput.ac.za
Background: The role of physiotherapists in obstetrics and gynecology is pivotal. However, utilization of their capabilities depends on the cooperation of other health professionals in discharging their services to patients, who are the focus of the team. This study was designed to assess the attitude of obstetricians and gynecologists in south-western Nigeria towards involving physiotherapists in the management of patients with obstetric and gynecologic conditions.

Methods: This was a descriptive survey of obstetricians and gynecologists from seven hospitals in south-western Nigeria. Sixty-seven participants, including 41 senior registrars and 26 consultants, participated in the study. More consultants (73.1\%) than senior registrars (46.3\%) had a good knowledge of the role of physiotherapists in obstetric and gynecological practice. All participants had general knowledge of the role of physiotherapists in obstetrics and gynecology, but a limited knowledge of specific conditions amenable to treatment by physiotherapists. More senior registrars had a better attitude $(73.2 \%)$ than consultants $(53.8 \%)$ towards involvement of physiotherapists in their practice, and $94.0 \%$ of the obstetricians and gynecologists utilized the services of physiotherapists, with referral of patients $(56.7 \%)$ mainly to physiotherapists working in general/state hospitals.

Conclusion: There is a need for better interaction and communication between physiotherapists and obstetricians and gynecologists, which could be achieved through clinical meetings, seminars, and workshops.

Keywords: obstetricians, gynecologists, attitude, practice, physiotherapists, referral

\section{Introduction}

Obstetric and gynecologic physiotherapy is a subspecialty in physiotherapy concerned with promotion of health throughout the child-bearing period, and helps the mother to adjust advantageously to the physical and psychologic changes of pregnancy and the post-natal period, so that the stresses of child-bearing are minimized. Physiotherapists specializing in obstetrics and gynecology require a mature blend of attributes, enabling women to disclose confidently what may be some of the most intimate and personal details of their lives. ${ }^{1}$ The role of the physiotherapist in obstetrics and gynecology involves pregnancy, labor, and the puerperium, and the preoperative and postoperative periods. ${ }^{2}$ However, the extent of utilization of physiotherapy services by obstetricians and gynecologists will depend on their knowledge and attitude towards physiotherapists. Physiotherapy in Nigeria operates on a referral system, so utilization depends on the attitudes of physicians towards physiotherapy. Physiotherapists in 
Nigeria hold a bachelor's degree, and some also have a master's degree or doctoral qualifications.

Utilization of individual professional skills depends on cooperation between health team members and the extent to which they value the knowledge of other team members in discharging their services to the patient, who is the main focus of the team. ${ }^{3}$ Therefore, there is a need for interdisciplinary cooperation between health care professionals, including obstetricians, gynecologists, midwives, physiotherapists, medical laboratory scientists, and social workers. ${ }^{4}$ Ogbona reported that physicians who trained in Nigeria had a poor knowledge and awareness of the physiotherapy profession compared with their counterparts who trained in the West. ${ }^{5}$ This limited knowledge may affect appropriate utilization of physiotherapy services by doctors, and could have an adverse effect on overall health care delivery in the country. In contrast, Ikhizama ${ }^{3}$ observed an increase in knowledge of physicians trained in Nigeria about physiotherapy services compared with that reported by Stephenson. ${ }^{4}$ However, both Ogbona and Abayomi observed that, despite the positive attitude of obstetricians in selected hospitals in Ibadan township and Ogun State towards physiotherapists, utilization of physiotherapy services was poor. ${ }^{5,6}$

Several studies have been carried out to assess the awareness, knowledge, attitudes, and utilization of physiotherapy services in various medical conditions. ${ }^{3,6,7}$ Inclusion of physiotherapy services in obstetrics and gynecology is pivotal to delivery of an optimal health care service. However, in Nigeria, there is limited information concerning the attitudes of obstetricians and gynecologists towards the involvement of physiotherapists in the management of patients with obstetric and gynecologic conditions as well as factors affecting their utilization of these services.

\section{Materials and methods}

This study was designed as a descriptive survey in which the participants were consultants and senior registrars in obstetrics and gynecology selected from seven hospitals in south-western Nigeria. Purposive sampling was used. The investigators identified the names of all senior registrars and consultants in the selected hospitals from hospital records. This was a population study because of the limited number of obstetricians practicing in the region, so all senior registrars and consultants were invited to participate, and all those who gave their consent were included. All participants had practiced obstetrics and gynecology for a minimum of 2 years. Sixty-seven $(52.76 \%)$ of the 127 senior registrars and consultants working in the selected hospitals participated in the study.
The hospitals selected were University College Hospital in Ibadan, Obafemi Awolowo University Teaching Hospital in Ile-Ife, Lagos University Teaching Hospital in Idi-Araba, Lagos, Ladoke Akintola University Teaching Hospital in Osogbo, Olabisi Onabanjo University Teaching Hospital in Sagamu, the Federal Medical Centre in Idi-Aba, Abeokuta, and Lagos State University Teaching Hospital in Ikeja, Lagos. These hospitals are located in the south-western part of Nigeria, and the majority of obstetricians in the country are trained and located in these institutions. The study instrument was a 28-item self-reported questionnaire in the English language adapted from a standardized questionnaire used in previous work. ${ }^{6}$ The questions were selected from the earlier questionnaire, the language of which was modified to suit the Nigerian context, with addition of some other items deemed to be relevant. The questionnaire was then presented at a seminar for expert face and content validation. Expert consensus was reached and the questionnaire was piloted in another location outside the study population. This was done on two occasions within one week to test the reliability of the instrument. The $\mathrm{r}$ value was 0.71 . The questionnaire was in three sections, ie, demographic characteristics, attitude of obstetricians and gynecologists to the role of physiotherapists in obstetrics and gynecology, and extent of utilization and factors affecting utilization of physiotherapy services by obstetricians and gynecologists. The attitude and utilization scales were in Likert format. There were no open-ended questions.

Ethical approval for the study was obtained from the institutional review committee at University College Hospital. Permission to conduct the study was obtained from the heads of departments of obstetrics and gynecology in each of the selected facilities. Informed consent was obtained from the participants in this study and the questionnaires were selfadministered. The questionnaires were collected immediately after completion, and those who could not complete their questionnaire immediately were contacted for collection on a return visit or through a contact person. The questionnaires were anonymous, so the researcher did not know who did or did not complete the questionnaire. The data were analyzed using descriptive statistics of frequency, percentages, and Chi-square inferential statistics, with the statistical significance level set at $P<0.05$.

\section{Results}

Sixty-seven participants, comprising $26(38.8 \%)$ consultants and $41(61.2 \%)$ senior registrars from seven selected hospitals, were included in this study. All questionnaires sent out 
were returned, giving a $100 \%$ response rate. Three $(4.47 \%)$ of the 67 questionnaires were not completed, so were not included in the analysis. The age range of the participants was $31-50$ (modal age range $31-40$ ) years. The study group included $61(91.0 \%)$ men and six $(9.0 \%)$ women. The majority $(75.5 \%)$ of the participants knew the role of physiotherapists in obstetrics and gynecology. The majority (80.6\%) of participants strongly agreed and $13.4 \%$ agreed to involvement of physiotherapists in obstetric palsy, followed by muscle weakness (79.1\% strongly agreeing and $20.9 \%$ agreeing) and gait postural alteration (77.6\% strongly agreeing and $22.4 \%$ agreeing, respectively). Further, $11.9 \%$ strongly agreed and $34.3 \%$ agreed to involvement of physiotherapists in the management of dyspareunia, while $34.3 \%$ strongly agreed and $13.3 \%$ agreed to involvement of physiotherapy in pelvic inflammatory disease. These findings are summarized in Tables 1 and 2 .

\section{Participant attitudes to physiotherapy services}

It was noted that $94.0 \%$ and $1.5 \%$ of participants strongly agreed and agreed, respectively, that physiotherapy service does not cause patients any harm, 92.5\% and 4.5\% strongly agreed and agreed, respectively, that physiotherapy cannot be replaced with drugs and instructions, and 92.5\% agreed that physiotherapists are competent to manage patients with obstetric and gynecologic conditions, as shown in Table 3. Also, $86.6 \%$ and $1.5 \%$ of gynecologic patients while 76.1 and $1.5 \%$ of obstetric patients strongly agreed and agreed, respectively, that physiotherapy service may contribute significantly to the complete well-being of gynecologic patients. Further, $80.6 \%$ of participants strongly agreed that a physiotherapy service would not be too expensive

Table I Distribution of participants by place of basic medical and postgraduate training and present hospital of practice

\begin{tabular}{llll}
\hline Name/place & Basic medical & Postgraduate & $\begin{array}{l}\text { Hospital } \\
\text { of practice }\end{array}$ \\
\hline UCH & $21(31.3 \%)$ & $16(23.9 \%)$ & $16(23.9 \%)$ \\
OATHS & $9(1.4 \%)$ & $15(22.4 \%)$ & $16(23.9 \%)$ \\
LUTH & $14(20.9 \%)$ & $12(17.9 \%)$ & $11(16.4 \%)$ \\
LASUTH & $0(0.0 \%)$ & $7(10.4 \%)$ & $8(11.9 \%)$ \\
FMC & $0(0.0 \%)$ & $4(6.0 \%)$ & $5(7.5 \%)$ \\
UNILORINTH & $9(13.4 \%)$ & $1(1.5 \%)$ & $0(0.0 \%)$ \\
LAUTH & $0(0.0 \%)$ & $1(1.5 \%)$ & $3(4.5 \%)$ \\
UNNTH & $4(6.0 \%)$ & $0(0.0 \%)$ & $0(0.0 \%)$ \\
UNIBENTH & $4(6.0 \%)$ & $0(0.0 \%)$ & $0(0.0 \%)$ \\
UNIJOSTH & $1(1.5 \%)$ & $0(0.0 \%)$ & $0(0.0 \%)$ \\
UK & $0(0.0 \%)$ & $3(4.5 \%)$ & $0(0.0 \%)$ \\
OOUTH & $5(97.5 \%)$ & $8(11.9 \%)$ & $8(11.9 \%)$ \\
\hline
\end{tabular}

Table 2 Distribution of participants' knowledge of the role of physiotherapists in obstetrics and gynecology

\begin{tabular}{|c|c|c|c|c|}
\hline & Yes & No & Not sure & Total \\
\hline \multicolumn{5}{|l|}{ Obstetric practice } \\
\hline Antenatal care & 55 (82.1\%) & $2(3.0 \%)$ & 10 (I4.9\%) & $67(100 \%)$ \\
\hline Parturition & 38 (56.7\%) & $10(14.9 \%)$ & $19(28.4 \%)$ & $67(100 \%)$ \\
\hline Postnatal care & 66 (98.5\%) & $0(0.0 \%)$ & I (I.5\%) & $67(100 \%)$ \\
\hline \multicolumn{5}{|l|}{ Gynecologic conditions } \\
\hline $\begin{array}{l}\text { Pelvic inflammatory } \\
\text { disease }\end{array}$ & $22(32.8 \%)$ & $23(34.3 \%)$ & $22(32.8 \%)$ & $67(100 \%)$ \\
\hline Uterine prolapse & 66 (98.5\%) & - & I (I.5\%) & $67(100 \%)$ \\
\hline Hysterectomy & 47 (70.1\%) & II (I6.4\%) & $9(13.4 \%)$ & $67(100 \%)$ \\
\hline $\begin{array}{l}\text { Cervical } \\
\text { incompetence }\end{array}$ & $5(7.5 \%)$ & 46 (68.7\%) & $16(23.9 \%)$ & 67 (100\%) \\
\hline
\end{tabular}

for patients, $50.7 \%$ and $6.0 \%$ strongly agreed and agreed, respectively, that physiotherapy is time-consuming, $56.7 \%$ and $10.4 \%$ strongly agreed and agreed, respectively, that physiotherapists should be allowed to attend surgical procedures for patients with gynecologic conditions, and 38.8\% and $16.4 \%$ strongly agreed and agreed, respectively, that physiotherapists should be allowed to attend the labor ward, while $41.8 \%$ and $13.4 \%$ strongly disagreed and agreed in that order that physiotherapists maintained adequate interprofessional relationships.

\section{Extent of utilization of physiotherapy services}

Sixty-three $(94.0 \%)$ of the participants reported having referred patients for physiotherapy, while four (6.0\%) had not done so (see Table 4$)$. Forty-eight (71.6\%) of participants had referred patients with a prescription, while $14(20.9 \%)$ had referred patients without a prescription. One (1.5\%) participant had referred patients with and without a prescription, and four $(6.0 \%)$ did not refer at all.

\section{Means of accessing physiotherapy}

Thirty-eight (60.3\%) participants referred patients to general/ state hospitals, eight (11.9\%) to their hospital of practice, six $(9.0 \%)$ to a private physiotherapy clinic, five $(7.5 \%)$ to both a private physiotherapy clinic and a general/state hospital, three $(4.5 \%)$ to a private physiotherapist, two $(3.0 \%)$ to a physical health educator, one $(1.5 \%)$ to both a private physiotherapy clinic and a private physiotherapist, and four (6.0\%) did not refer at all, as shown in Table 4.

\section{Factors affecting utilization of physiotherapy} Sixty-five $(97.0 \%)$ of the participants had a physiotherapy department in their hospital of practice, 17 (25.4\%) had a physiotherapy clinic within the vicinity of their 
Table 3 Participants' attitudes to physiotherapy service

\begin{tabular}{|c|c|c|c|c|c|}
\hline & SA & A & sw & D & SD \\
\hline Physiotherapy may not contribute significantly to complete well-being of obstetric & 10 & 5 & 0 & I & 51 \\
\hline patients & $14.9 \%$ & $7.5 \%$ & $0.0 \%$ & $1.5 \%$ & $76.1 \%$ \\
\hline Physiotherapy may not contribute significantly to complete well-being & 3 & 5 & 0 & I & 58 \\
\hline of gynecologic patients & $4.5 \%$ & $7.5 \%$ & $0.0 \%$ & $1.5 \%$ & $86.6 \%$ \\
\hline Physiotherapy may not contribute significantly to complete well-being & 2 & 3 & 0 & 0 & 62 \\
\hline with drugs and instructions & $3.0 \%$ & $4.5 \%$ & $0.0 \%$ & $0.0 \%$ & $92.5 \%$ \\
\hline \multirow[t]{2}{*}{ Physiotherapy is too expensive to be afforded by my patients } & 8 & 5 & 0 & 0 & 54 \\
\hline & $11.9 \%$ & $7.5 \%$ & $0.0 \%$ & $0.0 \%$ & $80.6 \%$ \\
\hline \multirow[t]{2}{*}{ Physiotherapy is time-demanding } & 34 & 4 & 0 & 0 & 29 \\
\hline & $50.7 \%$ & $6.0 \%$ & $0.0 \%$ & $0.0 \%$ & $43.3 \%$ \\
\hline \multirow[t]{2}{*}{ Physiotherapists should be allowed to attend the labor ward } & 26 & 11 & 0 & 0 & 30 \\
\hline & $38.8 \%$ & $16.4 \%$ & $0.0 \%$ & $0.0 \%$ & $44.8 \%$ \\
\hline Physiotherapy should be allowed to attend some surgical operations for gynecologic & 38 & 7 & 0 & 0 & 22 \\
\hline patients & $56.7 \%$ & $10.4 \%$ & $0.0 \%$ & $0.0 \%$ & $32.8 \%$ \\
\hline \multirow[t]{2}{*}{ Physiotherapists are not competent to manage my patients } & 3 & 2 & 0 & 0 & 62 \\
\hline & $4.5 \%$ & $3.0 \%$ & $0.0 \%$ & $0.0 \%$ & $92.5 \%$ \\
\hline \multirow[t]{2}{*}{ Physiotherapy will cause harm to my patients } & 2 & I & 0 & I & 63 \\
\hline & $3.0 \%$ & $1.5 \%$ & $0.0 \%$ & $1.5 \%$ & $94.0 \%$ \\
\hline \multirow[t]{2}{*}{ Physiotherapists have been adequate in their interprofessional relationships } & 28 & 9 & I & 0 & 29 \\
\hline & $41.8 \%$ & $13.4 \%$ & $1.5 \%$ & $0.0 \%$ & $43.3 \%$ \\
\hline
\end{tabular}

Abbreviations: SA, strongly agree; A, agree; SW, somewhat; D, disagree; SD, strongly disagree.

hospital, and $63(94.0 \%)$ had physiotherapists as close friends. Thirty-four $(50.7 \%)$ participants reported that the physiotherapy service in their hospital of practice is not too expensive and $62(92.5 \%)$ considered that the physiotherapy service had not worsened the condition of their patients. Thirty-one $(46.3 \%)$ of the respondents reported that there were not enough physiotherapists in their hospital of practice to cover the obstetrics and gynecology wards. Forty-seven $(70.1 \%)$ had worked

Table 4 Utilization of physiotherapy services by obstetricians and gynecologists

\begin{tabular}{llll}
\hline $\begin{array}{l}\text { Means of referral } \\
\text { of patients }\end{array}$ & Frequency & Percentage & $\begin{array}{l}\text { Cumulative } \\
\%\end{array}$ \\
\hline $\begin{array}{l}\text { Private physiotherapy } \\
\text { clinic }\end{array}$ & 6 & 9.0 & 9.0 \\
Private physiotherapist & 3 & 4.5 & 13.5 \\
General/state hospitals & 38 & 56.7 & 70.2 \\
Physical health educator & 2 & 3.0 & 73.2 \\
Hospital of practice & 8 & 11.9 & 90.5 \\
I and 3 & 5 & 7.5 & 85.5 \\
2 and 3 & 1 & 1.5 & 100.0 \\
Total & 63 & 94.0 & \\
No referral & 4 & 6.0 & \\
Mode of referral & & & \\
With prescription & 48 & 71.6 & 76.2 \\
Without prescription & 14 & 20.9 & 98.4 \\
Both & 1 & 1.5 & 100.0 \\
Total & 63 & 94.0 & \\
Neither & 4 & 6.0 & \\
Total & 67 & 100.0 & \\
\hline
\end{tabular}

previously with physiotherapists in the management of obstetric patients, while 49 (73.1\%) had worked previously with physiotherapists in the management of gynecologic patients. Forty-five $(67.2 \%)$ of the participants reported that a physiotherapy training program existed as a degree course in their college of basic medical training. However, only 10 (14.9\%) had physiotherapists posted in their hospitals and seven (10.4\%) had attended ward rounds with physiotherapists, while $56(83.6 \%)$ had a physiotherapy training program in their institution of residency training (see Table 5).

\section{Discussion}

\section{Knowledge of role of physiotherapy in obstetrics and gynecology}

Our findings indicate that consultants tend to be more aware and have better knowledge than senior registrars about the role of physiotherapy in obstetrics and gynecology due to exposure resulting from years of experience. The majority (79.1\%) of participants knew of the role of physiotherapists in obstetrics, with postnatal care having the highest score (98.5\%), followed by antenatal care $(82.1 \%)$ and parturition $(56.7 \%)$. These findings agree with those of another report. ${ }^{6}$ We found that $66(98.5 \%)$ of participants knew the role of physiotherapy in uterine prolapse, 47 (70.1\%) in hysterectomy, 22 (32.8\%) in pelvic inflammatory disease, and five $(7.5 \%)$ in cervical incompetence, indicating 
Table 5 Factors affecting extent of utilization of physiotherapy by participants

\begin{tabular}{|c|c|c|c|}
\hline Questions 15-26 & Yes & No & Not sure \\
\hline Physiotherapy service is too expensive & $3(4.5 \%)$ & $34(50.7 \%)$ & $30(44.8 \%)$ \\
\hline There are enough physiotherapists in my hospital to cover the & $10(14.9 \%)$ & $31(46.3 \%)$ & $26(38.8 \%)$ \\
\hline \multicolumn{4}{|l|}{ obstetrics and gynecology ward } \\
\hline Physiotherapy has worsened the condition of my patient before & I (I.5\%) & $62(92.5 \%)$ & $4(6.0 \%)$ \\
\hline Presence of physiotherapy degree program in college of training & $45(67.2 \%)$ & $15(22.4 \%)$ & 7 (10.4\%) \\
\hline Has physiotherapy posting & $10(14.9 \%)$ & $49(73.1 \%)$ & $8(11.9 \%)$ \\
\hline Does physiotherapist go on ward round with doctors & $7(10.4 \%)$ & $51(76.1 \%)$ & $9(13.4 \%)$ \\
\hline Worked with a physiotherapist in management of obstetric patients & $47(70.1 \%)$ & $18(26.9 \%)$ & $2(3.0 \%)$ \\
\hline Worked with a physiotherapist in the management of gynecology patient & $49(73.1 \%)$ & $16(23.9 \%)$ & $2(3.0 \%)$ \\
\hline Is there physiotherapy training/clinical department in your hospital & $56(83.6 \%)$ & $7(10.4 \%)$ & $4(6.0 \%)$ \\
\hline Presence of physiotherapy department in your hospital of training & $65(97.0 \%)$ & $0(0.0 \%)$ & $2(3.0 \%)$ \\
\hline Have a physiotherapist as close friend & $63(94.0 \%)$ & $4(6.0 \%)$ & $0(0.0 \%)$ \\
\hline Presence of physiotherapy clinic within vicinity of hospital of practice & $17(25.4 \%)$ & $0(0.0 \%)$ & $50(74.6 \%)$ \\
\hline
\end{tabular}

that participants were knowledgeable about the role of physiotherapy in obstetrics and gynecology. However, the low score observed for knowledge of the role of physiotherapy in pelvic inflammatory disease indicates that although obstetricians and gynecologists had general knowledge of the role of physiotherapy service, they had limited knowledge with regard to specific conditions. This also shows that obstetricians had not been involving physiotherapists in the management of conditions such as pelvic inflammatory disease. It was observed that of all the 28 obstetric and gynecologic conditions listed, 80\% strongly agreed about the role of physiotherapists in obstetric palsy. This is consistent with a previous report that physiotherapy is the main management modality for this condition. ${ }^{8}$ However, it is noteworthy that $43.4 \%$ and $41.8 \%$ of the participants did not agree about the role of physiotherapy in the management of episiotomy care perineal tears, respectively, even though it has already been pointed out that management of episiotomy requires more physical therapy than is currently appreciated. $^{8}$

\section{Attitude of participants to role of physiotherapy in obstetrics and gynecology}

Most of our study participants $(86.6 \%$ and $76.1 \%$, respectively) agreed that patients with obstetric and gynecologic conditions also require physiotherapy services. This is in agreement with two other reports. ${ }^{6,7}$ The majority of participants strongly agreed that physiotherapy would not cause harm to patients, and $92.5 \%$ strongly agreed that physiotherapy services cannot be replaced with drugs and instructions, and that physiotherapists are competent to manage obstetric and gynecologic conditions. More than $80 \%$ of participants strongly agreed that a physiotherapy service is not expensive and could be afforded by patients, while $50.7 \%$ considered it to be time-consuming. Also, $56.7 \%$ of participants strongly agreed that physiotherapists should be allowed to attend surgical procedures for patients with gynecological conditions, and $38.8 \%$ strongly agreed that physiotherapists should be allowed to attend the labor ward. It is agreed that physiotherapists can attend the labor ward, but should not interfere in any way in its normal operation but merely reinforce to the mother the teaching she had received in the antenatal period. Underutilization of physiotherapy may be due to limited knowledge on the part of obstetricians and gynecologists about the role of physiotherapists in parturition. Further, $41.8 \%$ of participants strongly agreed that physiotherapists have not performed adequately in their interprofessional relationships. This is indicative of a need for improved communication in the form of seminars, workshops, and attendance at grand rounds.

\section{Extent of utilization of physiotherapy services by participants}

The majority (94.0\%) of participants referred patients for physiotherapy, while $6.0 \%$ did not, and this could be due to the fact that the participants had better knowledge, a better attitude, and hence improved utilization of physiotherapy service. Most (76.2\%) of the participants referred obstetric and gynecologic patients with a prescription while $20.9 \%$ referred patients without a prescription, and the majority of the participants referred patients to general/state hospitals. This could be due to nonavailability of a department of physiotherapy in their hospitals of practice. Our findings in this regard are consistent with those of Adegoke. ${ }^{9}$ Referral with a prescription does not show regard for professionalism and needs to be investigated. 


\section{Factors affecting participant utilization of physiotherapy services}

Ninety-seven percent of the participants had a physiotherapy department in their hospital of practice, $94.0 \%$ had physiotherapists as close friends, $83.6 \%$ had a physiotherapy training program in their institution of residency, $73.1 \%$ and $70.1 \%$ had worked with physiotherapists before in the management of gynecologic patients and obstetric patients, respectively, $67.2 \%$ had physiotherapy as a degree program in their school of basic medical training, and $92.5 \%$ noted that physiotherapy had not worsened the condition of their patients. These factors could have influenced utilization of physiotherapy services in a positive way. It is noteworthy that only $14.9 \%$ of the participants had physiotherapy postings in their hospital and only $10.4 \%$ went on ward rounds with physiotherapists. It was observed that the present status of the participants resulted in better knowledge of the role of physiotherapy service in obstetrics and gynecology but not necessarily their attitudes. Senior registrars had a better attitude than consultants towards the role of physiotherapists in obstetrics and gynecology, despite their lesser knowledge. This indicates that better knowledge does not necessarily translate into a positive attitude.

\section{Conclusion}

Obstetricians and gynecologists in south-western Nigeria have a general knowledge of physiotherapy services in obstetrics and gynecology. They also demonstrate a positive attitude towards involvement of physiotherapists in the management of patients with obstetric and gynecologic conditions. However, their knowledge about the value of a physiotherapy service in specific conditions is limited. Physiotherapy posting during basic medical training and better interaction between obstetricians, gynecologists, and physiotherapists in the form of seminars, workshops, and grand rounds, could enhance knowledge and attitudes of obstetricians towards involvement of physiotherapists in patient management.

\section{Disclosure}

The authors report no conflicts of interest in this work.

\section{References}

1. Mantle J, Haslam J, Barton S. Physiotherapy in Obstetrics and Gynaecology. Edinburgh, Scotland: Elsevier Health Sciences; 2004.

2. Barlow B, Colgan A, Cox D. The work of the obstetric physiotherapist. Physiotherapy. 1978;64:229-230.

3. Ikhizama TO. Unpublished dissertation. Ibadan, Nigeria: Department of Physiotherapy, Faculty of Clinical Sciences, College of Medicine, University of Ibadan; 1995.

4. Stephenson PS. Emotional care of pregnant women. Can Fam Physician. 1972;18:70-71.

5. Ogbona PU. Physiotherapy services. Unpublished MSc thesis. Ibadan, Nigeria: Department of Physiotherapy, Faculty of Clinical Sciences, College of Medicine, University of Ibadan; 1984.

6. Abayomi F. Awareness, attitude and utilization of physiotherapy services by obstetricians in selected hospitals. Unpublished MSc thesis. Ibadan, Nigeria: Department of Physiotherapy, Faculty of Clinical Sciences, College of Medicine, University of Ibadan; 2001.

7. Odunaiya NA, Atoro F, Ogunlano MO. Using exercises to management diabetes mellitus: physicians' attitude and practice. Fisioterapi. 2004;1: 23-25.

8. Babarinsa IA. The nature and dimension of disorders in obstetrics requiring physical therapy. Physioray. 1998;2:35-38.

9. Adegoke BOA. Utilisation of physiotherapy services in Nigeria. Physioray. 1998;2:5-6.
International Journal of Women's Health

\section{Publish your work in this journal}

The International Journal of Women's Health is an international, peerreviewed open-access journal publishing original research, reports, editorials, reviews and commentaries on all aspects of women's healthcare including gynecology, obstetrics, and breast cancer. The manuscript management system is completely online and includes

\section{Dovepress}

a very quick and fair peer-review system, which is all easy to use. Visit http://www.dovepress.com/testimonials.php to read real quotes from published authors. 